JUILLET, L., « El presidente del consejo europeo: evolución política y jurídica desde I974 a 20I0», REDUR 8, diciembre 2010, págs. 39-6I. ISSN i695-078X

\title{
El PResidente del CONSEjo EURopeO: EVOlUCión POlítica Y JURÍdiCA DESDE 1974 A 2010
}

\author{
Laurent JUILLET \\ COORDINADOR GENERAL DE LA SECCIÓN ESPAÑOLA EUROS DU VILLAGE. DOCTOR EUROPEUS \\ UNIVERSIDAD DE SALAMANCA Y BURDEOS
}

\begin{abstract}
SUMARIO: I. Introducción. II. La mutación del modelo jurídico de Presidente del Consejo Europeo. II.I La decadencia del modelo de la «personificación estatal» del Presidente del Consejo Europeo. II.2 La ilusión del modelo de la «personificación personal» del Presidente del Consejo Europeo II.3 La inadecuación del modelo de «Presidente- Primus Inter Pares» II.4 La renovación del modelo de «Presidente- Praesidens». III. La persistencia de la debilidad política del Presidente del Consejo europeo. III.I El constante declive carismático de los líderes de la Unión europea. III.2 La frágil emergencia de una filiación política. IV. La imperfección del sistema de designación. IV.r La pérdida de la ilusión democrática con la designación por lista del Presidente del Consejo Europeo. IV.2 La insuficiencia del carácter democrático de la elección del Presidente del Consejo Europeo. IV.3 El no-reconocimiento convencional de la designación por lista del Presidente del Consejo Europeo como miembro del Consejo Europeo. IV.4 El reconocimiento convencional de la elección del Presidente del Consejo Europeo como miembro del Consejo Europeo. V. Conclusiones.
\end{abstract}

RESUMEN: La evolución institucional que ha conocido la presidencia del Consejo Europeo desde hace más de treinta años, ha modificado sus rasgos y caracteres jurídicos propios. Con la entrada en vigor del Tratado de Lisboa, el presidente del Consejo europeo se ha impuesto como el «mascaron de proa institucional» del Consejo europeo. Sin embargo, y aunque el Presidente del Consejo europeo aparezca hoy como una figura política y jurídica emergente en el escenario institucional europeo, esta figura necesita consolidarse. Por una parte, la mutación del modelo jurídico de Presidente del Consejo europeo ilustra esta evolución en particular con la decadencia que ha sufrido el modelo de «personificación estatal» del Presidente del consejo europeo y la inadecuación del modelo de «presidente-primus inter pares» durante el periodo pre-Lisboa. Pero la necesaria consolidación de esta figura institucional se transparenta con la ilusión del modelo del «personificación personal» del Presidente del Consejo europeo y la renovación del modelo de «Presidente-Praesidens». Por otra parte, la imperfección del sistema de designación del presidente del Consejo Europeo, cumulado con la persistencia de la debilidad política del Presidente del Consejo Europeo, impide una plenitud institucional satisfactoria de esta figura relevante de la Unión Europea. Concretamente, el constante declive carismático de los líderes de la Unión Europea, la frágil emergencia de una filiación política constituyen los dos principales frenos a esta evolución.

PALABRAS CLAVE: Unión europea, Consejo europeo, Presidente del Consejo europeo, evolución institucional.

KEYWORDS: European Union, European council, European council President, institutional evolution

\section{Introducción}

Cuando solo quedan unas semanas para que se cumpla el primer año de mandato del Presidente Van Rompuy a la cabeza del Consejo europeo, resulta pertinente hacer una pequeña valoración sobre la evolución política y jurídica que ha sufrido este cargo desde 
I974, apreciándola a la luz de las novedades institucionales introducidas por el Tratado de Lisboa.

El Presidente del Consejo Europeo ha sido durante años la «arlesienne» ${ }^{\mathrm{T}}$ de las instituciones europeas y, a pesar de la pompa y del aparato que sugiere la evocación de su cargo, es seguramente el miembro del Consejo Europeo más enigmático y finalmente el más desconocido. En efecto, si en la práctica, la existencia del Presidente del Consejo Europeo se puede comprobar desde el principio de la actividad del Consejo Europeo, su reconocimiento legal o convencional aparece por primera vez en el Tratado de Maastricht y se encuentra perennizado claramente en el Tratado de Lisboa de 2007. Además, las referencias a este miembro del Consejo Europeo en la prensa europea son numerosas y, la denominación del cargo entre los ciudadanos europeos es conocida. Pero en realidad, la identificación física y jurídica de este personaje es casi inexistente ${ }^{2}$.

Para enfocar este estudio, cabe constatar que el diseño institucional parece hacer del Presidente del Consejo Europeo un cargo más bien prestigioso que extraordinario.De hecho su papel, que no analizaremos aquí, es más bien de preparación y de animación de las reuniones, así como de vigilancia y de representación. Sin embargo, existe una voluntad equivocada de asemejar al Presidente del Consejo Europeo con un Presidente nacional Jefe de Estado. Es una idea errónea muy difundida que se encuentra también en las declaraciones de los más altos representantes europeos. Así por ejemplo, el propio padre del Consejo Europeo, el Presidente Giscard d'Estaing, participó en esta equivocación, poniendo al mismo nivel los Presidentes rusos y norteamericanos y el Presidente del Consejo Europeo ${ }^{3}$. Sin embargo, en ningún momento, el Presidente del Consejo Europeo debe ser considerado como el jefe de la Unión Europea o como un «súper Presidente» de Europa, con grandes poderes ejecutivos, similar al modelo del Presidente de los Estados Unidos. En cambio, es el Presidente del Consejo Europeo, es decir, el Presidente del colegio quien representa la «autoridad política suprema» ${ }^{4}$ en la Unión Europea ${ }^{5}$.

\section{La mutación del modelo jurídico de Presidente del Consejo Europeo}

La evolución política y jurídica de la figura del Presidente del Consejo europeo se puede apreciar primero por la mutación de su modelo jurídico. El estudio de la mutación del modelo jurídico de Presidente del Consejo Europeo es esencial para entender las ambigüedades de esta función y su carácter institucional peculiar.

Para apreciar esta mutación se debe tomar en cuenta el criterio de la evolución desde la creación del Consejo Europeo, insistiendo sobre la costumbre y los datos convencionales que han permitido diseñar el tipo de personalización del Presidente del

\footnotetext{
${ }^{\mathrm{I}}$ Este galicismo está utilizado para referirse a una persona o una cosa que tiene una importancia y un papel trascendente pero que nunca se deja ver.

${ }^{2}$ Así, curiosamente, el comunicado de Paris de I974 no menciona la existencia de dicho Presidente, Vid. «Resolución en ocasión de la Conferencia de los jefes de Estado o de gobierno que tendrá lugar en París los 9 y Io de diciembre de I974», Presidencia del gobierno centro de estudios políticos y constitucionales [en línea], disponible en : <http://www.cepc.es/rap/Publicaciones/Revistas/5/RIE_002_002_267.pdf>, (consultado en julio de 2008).

${ }^{3}$ Vid. V. GISCARD d'ESTAING, La Constitution pour l'Europe, Paris : Albin Michel, 2003, p. 56.

${ }^{4}$ Vid. P. De SCHOUTHEETE, H. WALLACE, Le Conseil européen, Groupement d'études et de recherches, Notre Europe, $n^{\circ} \mathrm{I} 9$, septembre 2002.

${ }^{5}$ Notar el orden jerárquico de los miembros del Consejo europeo establecido por el Tratado modificador. El Presidente del Consejo está en segunda posición después de los Jefes de Estado y de Gobierno como en posición de sumisión.
} 
Consejo Europeo y revelando los criterios originales que permiten facilitar la identificación del cargo. Así, desde I974, la ausencia de reforma ha instalado de manera duradera una «personificación estatal» del Presidente del Consejo Europeo a la cual han participado todos los Estados miembros de la Unión. A partir del año 2000 este modelo aparece arcaico y desgastado. Sin embargo, con la reforma institucional impulsada en Lisboa, se propone un modelo esperanzador de «personalización personal» del Presidente del Consejo Europeo.

El segundo elemento que permite valorar la mutación del modelo jurídico de Presidente del Consejo Europeo es la categoría de presidencia a la que pertenece el Presidente del Consejo Europeo. Por categoría nos referimos a los rasgos y cualidades propios del jefe del Consejo Europeo que permiten clasificarlo y distinguirlo de otro tipo de clase de Presidente. Bajo el impulso de las ampliaciones de los últimos años, y del arrebato constitucional del inicio de los años 2000, surgió el debate sobre las categorías de presidencia a la que está o debería estar vinculado el Presidente del Consejo Europeo. El estudio de esta cuestión y la contribución a este debate pretenden situarse desde el punto de vista evolutivo de la pertenencia del Presidente del Consejo Europeo a una categoría de presidencia. Esto supone primero identificar las categorías a las que puede ser sometido el Presidente del Consejo Europeo. Luego, se podrán analizar los motivos que han conducido a los convencionales a inclinarse a favor de tal categoría y al abandono de tal otra. Quizás sea conveniente, recordar la categoría única a la que pertenecía el Presidente del Consejo Europeo hasta la entrada en vigor del Tratado de Lisboa. En efecto desde I974, el Presidente del Consejo Europeo siempre fue reconocido en la práctica y por los Tratados como un «Presidente-Primus Inter Pares». Sin embargo, el Tratado reformado de la Unión Europea propone un cambio de esta categoría, reconociendo lo que podríamos llamar un «PresidentePraesidens» para liderar el Consejo Europeo.

\section{II.I La decadencia del modelo de la «personificación estatal» del Presidente del Consejo Europeo}

De I974 hasta la entrada en vigor del Tratado de Lisboa, estaba establecido que «el Consejo Europeo se reunirá (...) bajo la presidencia del Jefe del Estado o de Gobierno del Estado miembro que ejerza la presidencia del Consejo» ${ }^{6}$. Según estas disposiciones, la personificación del Presidente del Consejo Europeo se hace en función del Jefe del Estado o de Gobierno del Estado miembro que está al mando del Consejo de la Unión Europea. Esto significa que, en teoría, el Presidente del Consejo Europeo goza de una «personificación personal».

En realidad, en la práctica, la figura del Presidente del Consejo Europeo es uno de los Estados miembros de la Unión Europea y no realmente una persona ${ }^{7}$. Dicho de otro modo, esto significa que el Presidente del Consejo Europeo goza de lo que se podría llamar una «personificación estatal». Así, por ejemplo, si se pueden recordar al Presidente Mitterrand como Presidente de la República Francesa, o al Presidente González como Presidente del Gobierno español, en cambio, estos dos personajes no son mencionados como Presidentes del Consejo Europeo. De hecho, los medios de comunicación, y los ciudadanos prefieren recordar y hablar de «la primera presidencia española», o de «la tercera presidencia francesa», en vez de nombrar personalmente al Presidente del Consejo Europeo.

\footnotetext{
${ }^{6}$ Según las disposiciones del artículo D o 4 del Tratado de la Unión europea. Vid. texto del TUE disponible en línea in : «Tratado sobre la Unión europea, versión consolidada en 2002», Diario Oficial, n C325, 24 diciembre 2002 .

${ }^{7}$ Aunque según los Tratados el Presidente es un hombre y más precisamente el Jefe de Estado o de Gobierno de uno de los Estados miembros de la Unión europea.
} 
En la actualidad más reciente, esta tendencia se ha ido confirmando. En efecto, no se ha hablado del Presidente Chirac o del Presidente Aznar para referirse al Presidente del Consejo Europeo. En cambio, se hizo referencia a la presidencia francesa o a la presidencia española, confirmando así la preferencia por una personificación estatal a la personificación personal habitualmente utilizada. La existencia de una personificación estatal del Presidente del Consejo Europeo constituye una originalidad que supone dos comentarios.

Por una parte, la personificación estatal del Presidente del Consejo Europeo constituye una ventaja notable para el Estado que mediante su Jefe de Estado o de Gobierno, ejerce la presidencia. En efecto, el hecho de que la presidencia del Consejo Europeo pertenezca a un Jefe de Estado o de Gobierno miembro de la Unión Europea permite convertir el ejercicio de la presidencia del Consejo Europeo en un «asunto de prestigio nacional» ${ }^{8}$. Dicho de otro modo, el país encargado de la presidencia del Consejo Europeo se convierte al mismo tiempo en la sede oficial del Consejo Europeo' ${ }^{9}$ El Jefe de Estado o de Gobierno Presidente del Consejo Europeo, tiene entonces la oportunidad de ofrecer a su país una tribuna política de gran relevancia y demostrar a sus asociados sus capacidades de gestión y de dirección política de la Unión Europea. Se percibe, además, perfectamente el reto que constituye la presidencia del Consejo Europeo para los «países pequeños» o los nuevos países miembros de la Unión Europea, y las rivalidades existentes entre los «grandes» para recibir y organizar lo mejor posible el Consejo Europeo. Se entiende pues el concepto de "país Presidente anfitrión» que resulta de la práctica ${ }^{\text {ro }}$ y que favorece finalmente una personalización estatal de la presidencia del Consejo Europeo.

Por otra parte, es criticable el hecho de que esta personificación estatal del Presidente del Consejo Europeo haya fomentado la emergencia de un personaje totalmente desconocido por los ciudadanos europeos. En efecto, ¿quién podía decir el nombre del Presidente del Consejo Europeo en el ejercicio semestral ${ }^{\text {II }}$ ? Obviamente, este problema no significa que el Consejo Europeo funcione sin que un hombre o una mujer ejerzan el cargo de Presidente ${ }^{\mathrm{I} 2}$. Pero el problema es que la función nunca llegó a ser vinculada con un hombre o una mujer en concreto, que hubiera representado, para los pueblos europeos, el rostro del Consejo Europeo. Se percibe pues aquí el inconveniente de la personificación estatal a la que estaba sometido el Presidente del Consejo Europeo ya que la personificación personal de la función que existe y que está subyacente se encuentra totalmente ocultada.

Esta personificación estatal del Presidente del Consejo Europeo, es el resultado de una práctica no interrumpida desde I974. Los análisis anteriores, nos conducen a apreciar esta personificación estatal del Presidente del Consejo Europeo como una deriva idónea que ha propiciado la instalación progresiva del Consejo Europeo en el escenario institucional europeo. De este modo, el Consejo Europeo daba la impresión de estar protegido contra la tentativa de control de su presidencia por una persona identificable como individuo por los ciudadanos europeos.

Sin embargo, desde el inicio de los años 2000, este sistema ha demostrado sus límites lo que nos conduce a considerarlo como ampliamente superado. Primero porque la

\footnotetext{
${ }^{8}$ Según Etienne de Poncins, Vid. E. de PONCINS, Vers une Constitution européenne, Paris : 10/18, 2003.

${ }_{9}^{9}$ Aunque desde 2004, la sede «oficial» del Consejo europeo este en Bruselas.

1o Pero también de los Tratados europeos que han instaurado lo que se podría llamar un país Presidente anfitrión designado entre los Jefes de Estado o de Gobierno miembros de la Unión europea.

${ }^{\text {II }}$ Sobre todo cuando se trata de países pequeños.

${ }^{\mathrm{I} 2}$ De hecho, desde enero de I975, el Consejo europeo siempre ha tenido un hombre a su cabeza con el titulo de Presidente y no hubo ningún vacío del poder de la presidencia.
} 
idea que una persona pueda controlar el Consejo Europeo parece asustar menos ${ }^{\mathrm{I} 3}$. Luego, el desarrollo competencial del Consejo Europeo, así como el número de sus miembros han hecho que la personificación estatal de la presidencia corresponda a un modelo anticuado, que impide la maduración de la institución suprema de la Unión Europea. Por último, es preciso subrayar que el prestigio nacional que suponía el ejercicio de la presidencia del Consejo Europeo para un Estado miembro se ha convertido con los años en una práctica viciada. En efecto, la personificación estatal del Presidente del Consejo Europeo ha ido ejerciéndose de manera individual por los Estados miembros es decir al servicio prioritario de los intereses nacionales, sin preocuparse si estos sirven o no los intereses de la Unión Europea.

\section{II.2 La ilusión del modelo de la «personificación personal» del Presidente del Consejo Europeo}

El Tratado reformado de la Unión Europea, firmado en Lisboa, en 2007, aporta importantes modificaciones en cuanto a la identificación del Presidente del Consejo Europeo. En efecto, el artículo I5 del TRUE relativo al Consejo Europeo dispone que «El Consejo Europeo elegirá a su Presidente por mayoría cualificada para un mandato de dos años $\gamma$ medio, que podrá renovarse una sola vez. En caso de impedimento o falta grave, el Consejo Europeo podrá poner fin a su mandato por el mismo procedimiento. (...) El Presidente del Consejo Europeo no podrá ejercer mandato nacional alguno» ${ }^{\mathrm{I4}}$.

De momento la única referencia y ejemplo de Presidente del Consejo Europeo, que tenemos es el caso de Herman Van Rompuy. Es interesante recordar que antes que sea nombrado el presidente Van Rompuy, algunos autores se han atrevido en esbozar el perfil del Presidente del Consejo Europeo ideal. Las aspiraciones se inclinaban a favor de «una personalidad de experiencia, $y$ de alta cultura, entre $60 y 70$ años, que conozca bien el funcionamiento del Consejo Europeo por haber sido miembro en varias ocasiones. Desvinculado de la politica nacional del Estado miembro del que proviene y sin ambición de volver, cerca de sus homologas del Consejo Europeo, es capaz de entender y elaborar compromisos necesarios a un desarrollo armonioso de las reuniones del Consejo Europeo. (...) $\gg^{15}$

Por el momento es recomendable actuar con prudencia a la hora de hacer un análisis de estas disposiciones convencionales, ya que en la práctica se podría incurrir en aportar ciertos matices. Sin embargo, desde enero de 2010 se ha abandonado totalmente la personificación estatal de la presidencia y se ha implantado una personificación personal del Presidente del Consejo Europeo.

Esta nueva situación plantea un problema, en la medida en que esta modificación quita a los pequeños países, así como a los nuevos países entrantes en la Unión Europea, el privilegio «igualitario» de asegurar la presidencia del Consejo Europeo, fuente de un reconocimiento internacional y de un gran prestigio nacional.

A pesar de este inconveniente, es interesante notar las aportaciones benéficas que deberían acompañar la nueva generación de Presidentes del Consejo Europeo. En efecto, la principal consecuencia de este «nuevo» Presidente del Consejo Europeo tal y como lo define el artículo I5 del TRUE, es cortar los vínculos que existían entre el «hombre»

\footnotetext{
${ }^{13}$ Aunque existen reticencias por parte de los pequeños países de ver la presidencia del consejo europeo monopolizada por los grandes países.

${ }^{14}$ Vid. Tratado sobre la Unión europea, versión consolidada en 2008», Diario Oficial, nº C II5, 9 de mayo de 2008.

${ }^{15}$ Vid. E. de PONCINS, op. cit., p. I40.
} 
encargado de la presidencia y su país de origen ${ }^{\mathrm{r} 6}$. La ventaja de esta modificación es dar a todos los ciudadanos europeos y a los dirigentes internacionales una cara identificable con el Presidente del Consejo Europeo. Finalmente, la intención convencional es vincular directamente a una mujer o a un hombre, y no a un país, con la función de Presidente. Esta idea está reforzada con la inserción en el texto del Tratado de un apartado entero, totalmente dedicado al Presidente del Consejo Europeo ${ }^{\text {I7 }}$.

A priori, la personalización personal del Presidente del Consejo Europeo parece ser la solución ideal para evitar los problemas vinculados con la personalización estatal del Presidente del Consejo Europeo. De momento pues, formulamos grandes esperanzas sobre este nuevo modelo de presidencia del Consejo Europeo al considerar la emergencia de una personificación personal del Presidente del Consejo Europeo como una reforma y una evolución muy positiva para el Consejo Europeo. Sin embargo, debemos ser prudentes en la valoración de esta nueva identificación del Presidente del Consejo Europeo establecida en el Tratado de Lisboa. En efecto, con el tiempo, la práctica podría revelar algún vicio de esta personalización personal del Presidente del Consejo Europeo, y entonces imponer, algún ajuste institucional para mejorar la identificación del Presidente del Consejo Europeo.

\section{II.3 La inadecuación del modelo de «Presidente- Primus Inter Pares»}

Hasta la entrada en vigor del Tratado de Lisboa, el artículo 4 del Tratado de la Unión Europea disponía que, el Presidente del Consejo Europeo es el «Jefe del Estado o de Gobierno del Estado miembro que ejerza la presidencia del Consejo» ${ }^{18}$. Esta disposición significa que el Presidente del Consejo Europeo, está designado entre los miembros del Consejo Europeo y precisamente, entre los Jefes de Estado o de Gobierno de los Estados miembros de la Unión Europea.

El cargo de Presidente del Consejo Europeo se otorga pues a uno de los Jefes de Estado o de Gobierno que se convierte de este modo en la personalidad más importante dentro del grupo de los miembros del Consejo Europeo. Técnicamente, el Presidente del Consejo Europeo comparte el mismo cargo institucional que los demás miembros del Consejo Europeo $^{\text {19. }}$. Sin embargo, su cargo de Presidente del Consejo Europeo le otorga un reconocimiento de su autoridad y de su importancia especial por sus socios del Consejo Europeo. En este sentido, consideramos que el Jefe de Estado o de Gobierno que ejerce de Presidente «extraoficial» del Consejo Europeo es, en el seno del Consejo Europeo, un Presidente «Primus inter pares». Esta característica de la presidencia del Consejo Europeo, vigente desde 1974 , merece algunos comentarios.

En primer lugar, es interesante notar que como primus inter pares, el Presidente del Consejo Europeo se sitúa en el mismo nivel que los demás socios del Consejo Europeo. Esto puede interpretarse como una ventaja importante ya que permite que se mantenga una igualdad entre todos los miembros en el seno del Consejo Europeo, evitando así conflictos de legitimidad entre los miembros ${ }^{20}$. Además, siendo el Presidente del Consejo Europeo, el primero entre iguales, se evita la predominancia institucional de este cargo, tanto dentro del

\footnotetext{
${ }^{16}$ Id., p. I32 a 140.

${ }^{\mathrm{r} 7}$ No existía este apartado en los anteriores Tratados europeos.

${ }^{18}$ Vid. «Tratado sobre la Unión europea, versión consolidada en 2002», Diario Oficial, n C325, 24 diciembre 2002.

${ }^{19}$ Quedan excluidos obviamente los Ministros.

${ }^{20}$ Vid. Memorándum Benelux: Un marco institucional equilibrado para la Unión ampliada, más eficiente $y$ transparente, Bruselas : Secretaria Convención europea, 4 de diciembre de 2002. Texto disponible en línea en : http://register.consilium.eu.int/pdf/es/02/cvoo/00457es2.pdf
} 
Consejo Europeo como en el escenario institucional de la Unión Europea. De este modo, se mantiene un cierto equilibrio institucional general en la Unión Europea, evitando la confrontación y la rivalidad entre los altos cargos políticos, en particular con la Comisión.

Sin embargo, y en segundo lugar, cabe subrayar que este «Presidente-primus inter pares» sufre un problema de visibilidad y de reconocimiento institucional, bastante nefasto para la imagen del Consejo Europeo. De hecho, este problema de visibilidad se comprueba fácilmente ya que su existencia no está mencionada en los Tratados europeos y los pocos estudios doctrinales sobre el Consejo Europeo no contemplan su existencia. El claro inconveniente de esta categoría de Presidente es por lo tanto la ausencia de reconocimiento y visibilidad institucional que caracteriza a este cargo. Por otra parte, constituye también un problema el hecho de que el Presidente del Consejo Europeo como primero entre iguales no dé al cargo el carácter de líder que convendría a una institución tan relevante en el escenario institucional europeo como es el Consejo Europeo. Finalmente, cabe observar que el Presidente del Consejo Europeo por ser el primero entre los Jefes de Estado o de Gobierno miembros del Consejo Europeo está obligado a someterse a su cargo nacional. Esto supone una contraparte apremiante que da lugar a una falta de independencia en el ejercicio del cargo de Presidente del Consejo Europeo.

Sobre la base de las consideraciones anteriores, estimamos que el principal escollo de este Presidente-primus inter pares es no permitir una representación satisfactoria del Consejo Europeo, sobre todo en una Unión Europea que cuenta con veintisiete miembros. La dependencia con las obligaciones políticas nacionales, la ignorancia del cargo en los Tratados europeos y los efectos inducidos de este tipo de presidencia que limitan el desarrollo de un líder institucional han contribuido en diseñar un cargo «invisible» en total oposición con el prestigio institucional adquirido por el Consejo Europeo. Obviamente, la situación no puede seguir manteniéndose de esta forma, y una reforma del carácter del cargo de Presidente del Consejo Europeo nos parece necesaria. Sin embargo, al crear un cargo de Presidente con un resplandor institucional digno del Consejo Europeo, se corren riesgos importantes de desestabilización del equilibrio institucional de la Unión Europea, y de despertar entre los mandatarios europeos la codicia para este cargo prestigioso.

Así, la hipótesis de un statu quo sobre un «Presidente-primus inter pares» era impensable. No obstante, un Presidente del Consejo Europeo de pleno derecho, tal y como lo impone el texto del Tratado reformado de la Unión Europea, puede suscitar anhelos y temores.

\section{II.4 La renovación del modelo de «Presidente- Praesidens»}

El artículo I5 del TRUE dispone que «El Consejo Europeo elegirá a su Presidente por mayoría cualificada para un mandato de dos años y medio, que podrá renovarse una sola vez.(...) El Presidente del Consejo Europeo no podrá ejercer mandato nacional alguno» ${ }^{2 \mathrm{~T}}$. Este artículo, directamente inspirado del artículo I-22 del Tratado constitucional reconoce e instaura el cargo de Presidente del Consejo Europeo. Concretamente, esta disposición no crea un Presidente del Consejo Europeo puesto que existe el cargo de Presidente desde i974. En cambio, este artículo del Tratado de Lisboa considera al Presidente del Consejo Europeo no como un primus inter pares sino como un auténtico Praesidens en el sentido de jefe oficial que preside el Consejo Europeo.

\footnotetext{
${ }^{21}$ Vid. «Tratado sobre la Unión europea, versión consolidada en 2008», Diario Oficial, $\mathrm{n}^{\circ} \mathrm{C}$ II5, 9 de mayo de 2008.
} 
Este cambio de categoría del Presidente del Consejo Europeo no puede ser analizado adecuadamente por falta de perspectiva práctica del ejercicio del cargo. Sin embargo, este «Presidente-Praesidens» ha suscitado muchos comentarios en la doctrina y por parte de los actores europeos e impone pues que se hagan unos comentarios respecto a esta nueva figura del Consejo Europeo.

En primer lugar, y según Antoine Quero, Director de gabinete del Comisario Almunia, este Praesidens debería conferir al cargo «una mayor visibilidad y permanencia en el escenario institucional europeo» ${ }^{22}$. Esta característica que no existía cuando el Presidente del Consejo Europeo era el primus inter pares constituye pues un beneficio notable para la función al ofrecer al Consejo Europeo una encarnación personal duradera de su dirección, capaz de representarle en el escenario internacional. También, se puede apreciar una mejora del carácter del cargo de Presidente del Consejo Europeo en lo que la figura del Praesidens, tal y como está prevista en el Tratado de Lisboa, evita que la personalidad esté marcada por sus orígenes político y nacional. Este aspecto contribuirá sin duda ninguna en favorecer la independencia del cargo en la búsqueda del consenso y en el ejercicio de las misiones de arbitraje. Por fin, se debe subrayar que el reconocimiento de un «PresidentePraesidens» para ocupar la jefatura del Consejo Europeo debería permitir evitar la deriva que consistía para el Jefe de Estado o de Gobierno que ejercía de «Presidente-primus inter pares» dar la prioridad a los intereses nacionales. Con esta ventaja, se puede esperar que el Praesidens del Consejo Europeo desvinculado de los intereses nacionales pueda actuar en beneficio y en defensa de los intereses comunes europeos.

En segundo lugar, y ante la limitada práctica institucional, cabe reconocer que la figura del «Presidente Praesidens» suscita temores debidos a ciertos inconvenientes que conllevaría este nuevo cargo. La primera duda sobre el Presidente del Consejo Europeo es que plantea el riesgo de desfavorecer a los pequeños Estados en beneficios de los grandes Estados y crear, in fine, una violación del principio de igualdad vigente entre todos los Estados miembros. Esta desconfianza ha sido expresada oficialmente por los países del Benelux que consideran que «la nominación para un periodo determinado de un Presidente elegido del Consejo Europeo no constituye para los países del Benelux, una alternativa viable al sistema actual. Este sistema rompe con el principio de igualdad entre los Estados miembros con posibles repercusiones sobre las relaciones institucionales» ${ }^{23}$. Hay que reconocer que ninguna disposición en el texto del Tratado reformado sobre la Unión Europea de 2007 deja pensar que los grandes Estados podrían ser favorecidos frente a los pequeños Estados. Sin embargo, la ambición que podría despertar el prestigioso cargo de Presidente del Consejo Europeo sobre todo entre los grandes Estados, podría desembocar en una práctica perniciosa y constituir un real inconveniente del cargo de Praesidens del Consejo Europeo. En apariencia, la nominación del Presidente Van Rompuy, de origen belga, limita el alcance de este argumento.

El segundo temor provocado por este cargo de Presidente del Consejo Europeo es que se atente contra las competencias del Presidente de la Comisión Europea. Si así fuera, se imagina la amenaza que supondría la existencia de este «Presidente-Praesidens» para la cohesión del ejecutivo europeo. El sentimiento del Presidente Delors al respecto es que «por lo que se refiere al Presidente permanente del Consejo Europeo pienso que hay que ser muy prudente. Temo que este Presidente del Consejo Europeo complique y sobrecargue inútilmente las labores y los procedimientos de decisión. Además, es probable que la existencia de este Presidente

\footnotetext{
${ }^{22}$ Entrevista con Antoine Quero realizada en Bruselas el I7 de abril de 2007.

${ }^{23}$ Vid. «Memorando del Benelux firmado en La Haya el 4 de junio de 2002», Ministère luxembourgeois des Affaires Etrangères [en línea], disponible en :

$<$ http://www.mae.lu/images/biblio/biblio-59-I27.pdf>, (consultado en junio de 2008).
} 
del Consejo Europeo fomente riñas institucionales con la Comisión Europea y el Consejo de Ministros. Pienso que sería mucho más sencillo mejorar el trabajo en común del Consejo de Ministros de la Comisión y del Parlamento, limitando el recurso del Consejo Europeo únicamente para las grandes orientaciones» ${ }^{24}$. Aunque el Tratado de Lisboa no haya previsto modificaciones de las competencias respectivas de la Comisión y del Consejo Europeo, sería hipócrita rechazar las reservas sobre el riesgo potencial de que, en la práctica, el nuevo Presidente del Consejo Europeo contribuya a reforzar la Europa intergubernamental en detrimento de la Europa comunitaria, mediante una usurpación de las prerrogativas y misiones de la Comisión Europea. Desgraciadamente, y sin hacer deducciones precipitadas, la nominación del primer presidente permanente del Consejo europeo deja en evidencia una cierta inclinación de esta institución hacia un rumbo más intergubernamental, y ha revelado en varias ocasiones pruebas de rivalidades institucionales entre el presidente del Consejo europeo y el presidente de la Comisión europea.

El tercer inconveniente del «Presidente Praesidens» es que al ser designado fuera del Consejo Europeo podría sufrir de un déficit de legitimidad. En efecto, y como lo subraya Eneko Landaburu «iqué capacidad tendrá el Presidente del Consejo Europeo que será una persona muy estimable $y$ de gran relieve pero que no tendrá ni poder ni dinero?» ${ }^{25}$. En estas circunstancias, es probable que el Presidente del Consejo Europeo no goce de una legitimidad política suficiente en relación con la de los Jefes de Estado o de Gobierno y del Presidente de la Comisión ${ }^{26}$ en ejercicio. Además de este problema de peso político en el seno del propio Consejo Europeo, y en el marco de una probable competencia con el Presidente de la Comisión Europea, es probable que surja una oposición entre la legitimidad intergubernamental del Presidente del Consejo Europeo y la legitimidad supranacional del Presidente de la Comisión ${ }^{27}$. Esto constituiría obviamente un inconveniente añadido al reconocimiento de un «Presidente Praesidens» del Consejo Europeo.

Si no se pueden valorar aun todos los aspectos de esta categoría de «PresidentePraesidens», nos parece claro que el ejercicio de la presidencia del Consejo Europeo será modificado en los próximos años con posibles repercusiones en las relaciones con las demás instituciones de la Unión Europea. En efecto, aunque no tenga muchos poderes, el cargo de Presidente del Consejo Europeo tendrá un peso político notable debido al prestigio de la función otorgado por el Tratado de Lisboa. Pensamos que este peso político del Presidente del Consejo Europeo es necesario y corresponde a la evolución lógica del desarrollo institucional del Consejo Europeo. En este sentido, pues, expresamos una opinión favorable sobre el reconocimiento de este «Presidente-Praesidens». Sin embargo, y en reserva de comentarios futuros en función de la práctica institucional, nos parece totalmente imprescindible que el Presidente del Consejo Europeo se limite a sus funciones de conciliador, de organizador y de representante simbólico del Consejo Europeo.

En nuestra opinión, la creación de este «Presidente-Praesidens» no debe suponer la creación de un ejecutivo bicéfalo ya que por una parte la Comisión se encarga de la jefatura del poder ejecutivo mientras que el Consejo Europeo se limita a la jefatura de la Unión Europea. Dicho de otro modo, la realidad del poder «ejecutivo» debe imperativamente ser reservado a la Comisión Europea y a su Presidente y en ningún momento ser transferida al

\footnotetext{
${ }^{24}$ Entrevista con Jacques Delors ex Presidente de la Comisión, del 7 de febrero de 2007 en Paris.

${ }^{25}$ Entrevista con Eneko Landaburu, Director general de los asuntos exteriores a la Comisión europea, 20 de febrero de 2007 en Bruselas.

${ }^{26}$ Que puede reivindicar una legitimidad democrática debido a su elección por el Parlamento europeo.

${ }^{27}$ Esta situación crearía una fractura con la concepción habitual en la Unión europea de combinar intergubernamentalidad y supranacionalidad.
} 
Consejo Europeo y a su Presidente. Si ocurriera tal caso, se deberán tomar todas las medidas para incitar a los miembros del Consejo Europeo de actuar en conciencia y con razón para modificar esta deriva y acabar con la prepotencia de su Presidente.

Después de un año de mandato del Presidente Van Rompuy, y del estreno de la función del «Presidente-Praesidens» del Consejo Europeo, debe prevaler el optimismo frente a la posibilidad, que supone este nuevo cargo, de mejorar la actividad del Consejo Europeo y de dinamizar el funcionamiento de la Unión Europea. Así y sobre la base de la experiencia del Presidente Delors que reconoce que «nunca he sido más feliz como cuando habia un Presidente del Consejo Europeo fuerte» ${ }^{28}$, abogamos a favor «de la coexistencia fructuosa entre estos dos Presidentes» ${ }^{29}$.

\section{La persistencia de la debilidad política del Presidente del Consejo europeo}

Uno de los problemas a los que se enfrenta la figura del presidente del consejo europeo es una carencia de autoridad política. Esta debilidad política se puede comprobar a la luz de dos criterios. Primero, debemos considerar el criterio del carisma como uno de los elementos clave de la apreciación subjetiva de la capacidad del presidente del Consejo Europeo de imponerse en el escenario político e institucional europeo. Luego, es el criterio de la filiación política que analizaremos comprobando, en el caso del Presidente del Consejo europeo una frágil emergencia de este tipo de filiación.

\section{III.I El constante declive carismático de los líderes de la Unión europea.}

La noción de carisma tiene una connotación primera muy teológica ${ }^{30}$. En realidad, en este apartado, hacemos referencia a un sentido más bien político de la palabra carisma, refiriéndose a la influencia suscitada por una personalidad excepcional «que se singulariza por cualidades prodigiosas, por el heroísmo, $y$ otras particularidades ejemplares que hacen de él el jefe» ${ }^{31}$. El recurso al criterio del carisma es un medio usado tradicionalmente para apreciar los poderes y la autoridad de determinadas instituciones políticas. El uso de este criterio se ilustra en particular, a nivel nacional, para la institución de la Jefatura del Estado ${ }^{32}$. Pero

\footnotetext{
${ }^{28}$ Declaraciones en entrevista con Jacques Delors, op.cit.

${ }^{29}$ Es decir el Presidente del Consejo europeo y el Presidente de la Comisión. Declaraciones en entrevista con Jacques Delors, op.cit.

${ }^{30}$ Vid. LA REAL ACADEMIA ESPAÑOLA, Diccionario de la lengua española, Madrid: La Real Academia Española, I970.

${ }^{31}$ Vid. M. WEBER, Le savant et le politique, Paris : UGE, I959.

${ }^{32}$ En Francia, por ejemplo, la presidencia de Charles de Gaulle ilustra perfectamente el caso de una legitimidad carismática. Para el pueblo francés, el General era un hombre excepcional, héroe de guerra, liberador del país, modelo político y padre de la Constitución de la V República. Vid. C. de GAULLE, Mémoires de guerre, Paris : Le Grand Livre du Mois, Le Club, I999. Véase tambien A. PEYREFITTE, C'était de Gaulle, Paris : Le Grand Livre du Mois, Le Club, I994. Todos estos elementos han contribuido incontestablemente a la construcción progresiva de su legitimidad carismática en el país, legitimidad que ha favorecido la emergencia del concepto de gaullismo. Sobre este tema, véase Centre d'Information sur le Gaullisme [en línea], disponible en :

$<$ http://www.gaullisme.net/>, (consultado en julio de 2008). Otro elemento muy importante que merece ser señalado es la reivindicación explícita y el orgullo de esta legitimidad carismática por parte del General de Gaulle. Precisamente, los profesores Dominique Chagnollaud y Jean-Louis Quermonne citan en su libro un discurso de De Gaulle del 29 de enero de I960 donde aparece en uniforme militar y se refiere a «La legitimidad [carismática] que encarna desde hacen 20 años». Sobre el fondo y sobre la forma, el Presidente francés disemina referencias claras destinadas a subrayar la legitimidad carismática de la que goza. Vid. D. CHAGNOLLAUD, J-L. QUERMONNE, op.cit., p. I49.
}

En España, esta legitimidad carismática la tiene el Rey Juan Carlos I . Muchas personas reconocen en efecto la personalidad y la influencia excepcional del Rey Juan Carlos I . Vid. J. GARCIA ABAD, La soledad del Rey: 
todos los Jefes de Estado no pueden prevalerse de tener un aura carismática. En efecto, toda la dificultad de la existencia y del reconocimiento del carisma de un dirigente político es conseguir que el pueblo tenga y otorgue su confianza libre y no-partisana a su jefe.

La referencia global a los líderes de la Unión europea y no expresamente al Presidente del consejo europeo es voluntaria puesto que todos los presidentes del Consejo europeo han sido jefe de Estado o de gobierno de uno de los Estados miembros de la Unión. Enfocando la cuestión desde el punto de vista de las personas que han asumido el cargo de Presidente del consejo europeo, el carisma individual ha sido variable según las épocas y los miembros presentes en el Consejo Europeo ${ }^{33}$. Sin embargo, la historia del Consejo Europeo conserva la memoria de algunos de sus miembros que han asumido las funciones de presidente y que han demostrado por sus acciones y sus personalidades un verdadero carisma. Sin pretender establecer una lista exhaustiva, se pueden citar varios miembros del Consejo Europe ${ }^{34}$ que pueden ilustrar esta aura carismática.

Así, se pueden citar algunos Jefes de Estado o de Gobierno. Desde I974, se debe admitir que sólo muy pocos Jefes de Estado o de Gobierno han dejado un recuerdo memorable, capaz de otorgarles un fuerte carisma como miembro del Consejo Europeo. Entre estos privilegiados se puede citar a Margaret Thatcher. A su manera, el Primer ministro británico demostró su importante carisma en el seno del Consejo Europeo en particular por la fuerza y la intransigencia con la que defendió sus ideas ${ }^{35}$. El Presidente francés François Mitterrand y el Canciller alemán Helmut Kohl demostraron en un dúo histórico, sus capacidades especiales para conectar con los problemas europeos y darles soluciones. La complicidad entre ambos hombres y el simbolismo impactante de sus acciones les otorgaron un amplio carisma como miembros y presidentes del Consejo Europeo $^{36}$. Sin embargo, es importante notar que el lugar privilegiado que se han autootorgado las «parejas» franco-alemanas en el seno del Consejo Europeo no ha sido siempre acompañado por el reconocimiento de una fuerza carismática ${ }^{37}$. El Presidente del Gobierno

¿está la monarquía consolidada 25 años después de la Constitución?, Madrid : La Esfera de los Libros, 2004. Se atribuye esta confianza popular para este Rey, a la gestión del golpe de Estado del 23 F. Esta «fascinación» de los españoles para este hombre, y no realmente por la institución de la Corona que debe, según la constitución, representar, ha permitido denominar esta legitimidad carismática bajo el nombre de «Juan carlismo». Felipe González decía «No es la institución que ha subyugado a los españoles es el Rey» in J-L. De VILALLONGA, Le Roi, Paris : FIXOT, I993, p. I4. Curiosamente, el Rey de España no revindica esta fuente de legitimidad y aunque no le desagrada confesó estar bastante preocupado por el alcance que tiene el «Juan carlismo» en España. Véase id., p. I2 y 277.

${ }^{33}$ Es importante precisar ahora que un Jefe de Estado o de Gobierno puede ser a nivel nacional, en su país, un líder carismático, pero como miembro del Consejo europeo carecer de esta legitimidad.

${ }^{34}$ Se excluyen voluntariamente del estudio los Ministros nacionales y el Comisario europeo que tienen un papel secundario, así como el Ministro de asuntos exteriores de la Unión, por falta de elemento de análisis. El Ministro de asuntos exteriores de la Unión, según las disposiciones de la Constitución europea, es el nuevo miembro del Consejo europeo. Si entraran en vigor de alguna manera estas disposiciones es muy probable, que vista la importancia del cargo, la personalidad nombrada para este puesto pueda reivindicar, algún día, una legitimidad carismática.

${ }^{35}$ Para Jacques Delors, «Margaret Thatcher siempre ha tenido ideas muy claras sobre la evolución de la sociedad británica y sobre los límites de la integración europea» En nuestra entrevista, el ex Presidente de la Comisión recordó la relaciones difíciles con el Primer ministro británico en particular durante la Cumbre de Luxemburgo de 2 de diciembre de i985 y para las negociaciones del «paquet Delors I» entrevista con Jacques Delors, 7 de febrero de 2007, en París.

${ }^{36}$ Es cierto que el miembro francés y el miembro alemán siempre han representado un papel determinante en el Consejo europeo, siendo sus gestos y sus palabras objeto de mucha atención y respeto. Vid. «Foto de François Mitterrand y de Helmut Kohl cogidos de la manos, el 22 de septiembre de 1984 en Verdun», Cercle des européens [en línea], disponible en: <http://www.ceuropeens.org/Mitterrand-et-Kohl-a-Verdun.html>, (consultado en junio de 2008).

${ }^{37}$ Es el caso por ejemplo de la pareja Chirac/Shroeder. Esta falta de carisma provocó desconfianza y muchas críticas tanto entre los otros miembros del Consejo europeo como entre los ciudadanos europeos. Estas críticas, muy virulentas en la década I995-2005, han dado lugar al intento, sin futuro, de creación del «motor hispano 
español, Felipe González, así como el Primer ministro británico, Tony Blair ilustran de cierto modo también el carisma de los Presidentes del Consejo Europeo al gozar de un capital de esperanza de renovación política. Además, ambos líderes supieron utilizar sus cualidades personales para imponerse entre sus socios como miembros eminentes del Consejo Europeo. Por último, el Primer ministro luxemburgués, Jean-Claude Juncker, por su longeva presencia en el seno del Consejo Europeo y su credibilidad política ha adquirido una evidente autoridad entre sus socios europeos que le ha otorgado un real carisma a la hora de asumir la presidencia del Consejo Europeo.

Sin embargo, y a pesar de estas personalidades fuertes, es sorprendente constatar que no se recuerda precisamente a ninguno Presidente del consejo europeo por su influencia excepcional, sus hechos históricos o por sus cualidades prodigiosas a favor del Consejo Europeo y de la Unión. En realidad, la dificultad para los Presidentes del Consejo Europeo de adquirir una fuerza carismática se explica, al menos hasta la entrada en vigor del Tratado de Lisboa, por la limitación temporal excesiva de su mandato. Con un mandato semestral, es difícil lograr, como Presidente, dicho carisma y obviamente imposible reivindicarlo ${ }^{38}$. Esta situación podría ser modificada ${ }^{39}$, y es muy probable que, en el futuro, surjan Presidentes del Consejo Europeo que puedan asentar su poder sobre un aura carismática. La existencia y la variación del carisma individual de los miembros del Consejo Europeo conducen a formular unas observaciones.

En primer lugar, dicho carisma individual del presidente del Consejo europeo produce efectos sobre el Consejo Europeo como órgano colegial y sobre sus miembros. Así, por una parte, la emergencia de Presidentes fuertes del Consejo Europeo beneficia al Consejo Europeo en su conjunto, permitiendo impulsar con eficacia las acciones del Consejo Europeo y desarrollar proyectos ambiciosos e ideas novedosas. Por otra parte, esta aura carismática del Presidente tiende a difundirse entre todos los miembros del Consejo Europeo. En efecto, se puede decir que un presidente carismático arrastra a todos los miembros del Consejo Europeo en un círculo virtuoso que dinamiza la imagen y las acciones de cada miembro del Consejo Europeo.

Para ilustrar estas ventajas de la existencia de Presidentes carismáticos en el Consejo Europeo, se puede hacer referencia al periodo entre i985 y I995 durante el cual, a pesar de las dificultades socioeconómicas y geopolíticas, el Consejo Europeo conoció, una década de desarrollo y de plenitud incomparable. Por el contrario, la ausencia de Presidentes carismáticos en el Consejo Europeo, en el periodo I995-2005, ilustra el relativo inmovilismo del órgano supremo de la Unión Europea. Esta situación y los inconvenientes que supone, confirman la importancia de la existencia de un carisma para algunos miembros del Consejo Europeo y la necesidad que estos líderes puedan expresar con fuerza sus ideas y personalidades para dinamizar la acción del Consejo Europeo.

ingles» o «eje Madrid Londres» a principio de los años 2000 entre el Primer ministro británico Blair y el Presidente de Gobierno Aznar. Vid. C.P., «Zapatero, dernier defenseur de l'Axe franco-allemand», ARTE Histoire Q Société [en línea], I3 septembre 2004, disponible en : <http://www.arte.tv/fr/recherche/631048.html>, (consultado en junio de 2008).

${ }^{38}$ Lo demuestra el ejemplo de la presidencia irlandesa de Bertie Ahern; en solo 6 meses consiguió la proeza de concluir las negociaciones sobre la adopción de la Constitución europea, en un contexto diplomático muy difícil. Todos los miembros del Consejo europeo habían saludado la acción formidable e inesperada del entonces Presidente del Consejo europeo. Pero la emergencia tímida de lo que hubiera podido desembocar sobre una legitimidad carismática fue literalmente cortada por el fin del mandato semestral del Presidente Bertie Ahern.

${ }^{39}$ Con la adopción de las disposiciones del Tratado constitucional, que tiene previsto un Presidente del Consejo europeo permanente con un mandato de dos años y medio. En efecto, con este mandato de dos años y medio repetible, el Presidente del Consejo europeo debería tener el tiempo suficiente, y pues la posibilidad, para actuar y forjarse una legitimidad carismática en el seno del Consejo europeo. 
En segundo lugar, y a pesar de sus ventajas, la existencia de una fuerza carismática de ciertos miembros del Consejo Europeo puede crear situaciones de tensión que no pueden ser ignoradas. Por ejemplo, el carisma de un Jefe de Estado o de Gobierno en el seno del Consejo Europeo se puede percibir como una amenaza para los demás miembros al constituir un riesgo para la unidad del consenso en el seno del Consejo Europeo ${ }^{40}$. Otro riesgo posible es que el carisma de un presidente del Consejo Europeo acabe en una identificación demasiado fuerte del líder con el Consejo Europeo y que se produzca una personificación del órgano supremo de la Unión Europea ${ }^{4 \mathrm{r}}$. Otro problema que se puede plantear es que el presidente del Consejo Europeo que goce de este renombre carismático debilite la legitimidad política de sus demás socios en el seno del Consejo Europeo. Por último, la existencia de este carisma puede desembocar en que tal o cual miembro carismático esté bajo sospecha de querer apoderarse del control del Consejo Europeo ${ }^{42}$.

El criterio del carisma del Presidente del Consejo europeo es difícilmente manejable ya que depende totalmente de las personalidades políticas presentes en el Consejo Europeo. Sin embargo, valoramos muy positivamente la presencia de grandes miembros carismáticos en el seno del Consejo Europeo y, a partir de la experiencia de los años 85-95, reconocemos la necesidad y los beneficios procurados por la existencia de un carisma de los Jefes de Estado o de Gobierno miembros del Consejo Europeo ${ }^{43}$.

Obviamente, todos los miembros del Consejo Europeo no pueden gozar de esta aura carismática a título personal. Es el caso del actual presidente Van Rompuy. Sin embargo, la comparación de los miembros del Consejo Europeo de la década 85-95, con los de la década de $95-05^{44}$ destaca claramente una crisis del carisma individual de los miembros del Consejo Europeo. Lamentamos este declive del carisma entre los presidentes del Consejo Europeo porque tiene consecuencias que se repercuten en el buen funcionamiento de las instituciones y de las políticas europeas.

${ }^{40}$ Esto fue el caso entre el presidente francés Nicolas Sarkozy y el Primer ministro luxemburgues Jean Claude Juncker a finales de los años 2000; o del Primer ministro británico Margaret Thacher en los años ochenta, cuya obstinación llegó a complicar el alcance de consensos en el Consejo europeo y pues al fracaso de varias Cumbres.

${ }^{41}$ De cierto modo, esto pasó no en el Consejo europeo pero en la Comisión europea con Jacques Delors. En efecto, la Comisión europea era y sigue siendo identificada con la personalidad de Jacques Delors. En caso de que la presidencia del Consejo europeo deje de por turno, con la elección de un Presidente «fijo», el Consejo europeo podría conocer este fenómeno, con la elección de un Presidente con un gran carisma.

${ }^{42}$ Catherine Lalumière describe el ambiente de la Cumbre de Milán de junio de 1985 , y la ira de los miembros del Consejo europeo contra el Presidente francés y el Canciller alemán que han elaborado un texto sin haberlo concertado con los otros miembros del Consejo europeo. Eso ilustra la tentación de los dos líderes carismáticos de la época de tomar decisiones sin respetar las reglas del Consejo europeo y la interpretación de los otros Jefes de Gobierno que han denunciado un «push» franco alemán en el Consejo europeo. Vid. LALUMIERE Catherine, Secretaria de Estado de Asuntos europeos de Francia, entrevistada por DESCHAMPS Étienne, Paris, I7 de mayo de 2006, Centre Virtuel de la Connaissance sur l'Europe (CVCE) [en línea], disponible en : <http://www.ena.lu/mce.cfm>, (consultado en junio de 2008).

${ }^{43}$ Es evidente que los demás miembros del Consejo europeo deben estar siempre muy atentos sobre las posibles derivas de sus socios más carismáticos evitando que los líderes políticos vulneren las reglas de funcionamiento del Consejo europeo y que contribuyen a bloquear sistemáticamente la toma de decisión y el alcance del consenso.

44 Tanto Nicole Fontaine (entrevista del 6 de diciembre de 2006 en Paris) como Eneko Landaburu (entrevista del 20 de febrero de 2007 en Bruselas) y que Antoine Quero (entrevista del I7 de abril de 2007 en Bruselas) han lamentado la ausencia de grandes líderes políticos carismáticos en el seno del Consejo europeo para dar un nuevo impulso al Consejo europeo. 


\section{III.2 La frágil emergencia de una filiación política}

El segundo criterio que permite apreciar la debilidad política del presidente del Consejo europeo desde un punto de vista subjetivo es la filiación. El análisis de este criterio consiste en apoyar la justificación y el poder actual de esta figura institucional, sobre filiaciones dinásticas o espirituales que legitiman la situación institucional de un órgano determinado. Por una parte, la filiación espiritual supone simplemente, por parte del que la tiene, una reivindicación explícita de la herencia y una voluntad clara de presentarse como el sucesor de un antecesor concreto, sin la necesidad de la existencia de un vínculo familiar ${ }^{45}$. Por otra parte, la filiación dinástica puede ser reivindicada por una persona, para la cual está comprobada la existencia de un vínculo familiar, y por lo tanto dinástico, con posibles antecesores y sucesores ${ }^{46}$.

La hipótesis de que el presidente del Consejo Europeo reivindique una filiación cualquiera es complicada dado que no es el Consejo europeo sino el mero representante de este órgano colegial. La reivindicación de una filiación en este caso solo deberá ser entendida como la expresión de la voluntad de una mujer o de un hombre que está al mando del Consejo europeo y que inscribe su mandato en la continuidad política de un ilustre antecesor.

Por una parte, se puede constatar que los Jefes de Estado o de Gobierno que han ejercido el cargo de Presidente del Consejo Europeo, tienen la voluntad de inscribirse en la continuidad de la obra iniciada por los padres fundadores de la Unión Europea. Así, en varias ocasiones en los discursos de los distintos miembros del Consejo Europeo ${ }^{47}$, existen reivindicaciones explícitas a la herencia espiritual de personajes como Jean Monnet o Robert Schuman, y ahora Jacques Delors. Por otra parte, y sobre la base de las instituciones nacionales, el Presidente del Consejo Europeo no puede reivindicar una filiación dinástica ya que el sistema de rotación hasta 2010 y el sistema de elección establecido en el Tratado de Lisboa, lo impiden formalmente. Es interesante subrayar que en el caso de los Jefes de Estado que han ejercido el cargo antes de la entrada en vigor del Tratado de Lisboa, hubiera podido caber el caso de un miembro con filiación dinástica. En efecto, son muchos los Jefes de Estado en Europa que ocupan esta función gracias a una filiación dinástica ${ }^{48}$. Sin embargo, en el Consejo Europeo, todos los miembros susceptibles de tener una filiación dinástica han sido sustituidos por los Jefes de Gobierno ${ }^{49}$.

${ }^{45}$ A título de ejemplo, las referencias a la legitimidad hereditaria sucesoria están particularmente utilizadas en Francia, ya que el sistema republicano impide una herencia dinástica del poder. Así, es algo bastante normal ver a los hombres políticos y concretamente a los Presidentes de la República, reivindicar «las herencias» de tal o tal personaje, presentándose como «su» sucesor político. El Presidente Mitterrand solía presentarse como el heredero directo de los grandes líderes de izquierda como por ejemplo Jaurès, Blum o Mendès France. El Presidente Chirac también utilizaba esta legitimidad hereditaria para presentarse como el sucesor del General de Gaulle. En cuanto al Presidente conservador Nicolas Sarkozy, se puede citar sus repetidas referencias a la herencia del histórico líder izquierdista Jean Jaurés.

${ }^{46}$ Por ejemplo, en el caso español, se puede referir al artículo 57 de la Constitución española que da una buena ilustración del funcionamiento de esta legitimidad hereditaria dinástica. Dice el artículo 57 : «La Corona de España es hereditaria en los sucesores de S.M. D. Juan Carlos de Borbón legitimo heredero de la dinastía histórica». Vid. «Constitución española de I978», Congreso de los Diputados [en línea], disponible en : $<$ http://narros.congreso.es/constitucion/constitucion/indice/index.htm>, (consultado en junio de 2008).

${ }^{47}$ Véase por ejemplo, BERLUSCONI Silvio, «Discurso del 4 de octubre de 2003 con motivo del inicio de la CIG», Presidencia Italiana de la U.E. de 2003 [en línea], Roma, 4 de octubre de 2003, disponible en :

<http://ueitalia2003/FR/LaPresidenzaInforma/Calendario/Io/4/doc_ev_4ottce>, (noviembre de 2004). Véase tambien F. MITTERRAND, Onze discours sur l'Europe 1982-1995, Napoli : Vivarium, I996.

${ }^{48}$ Así, por ejemplo, el Rey de España, como Jefe del Estado, con el mismo título que el Presidente de la República francesa, podría ser miembro del Consejo europeo.

${ }^{49}$ En realidad esta hipótesis tiene poca posibilidad de aplicarse a nivel individual debido a la condición constitucional de estos Jefes de Estado. 
Esta presentación permite hacer unas constataciones. Se puede comprobar que la filiación espiritual de los presidentes del Consejo Europeo es una realidad, mientras que se deduce lógicamente la inexistencia de filiación dinástica. Esto significa que la filiación de los presidentes del Consejo Europeo existe parcialmente. Esta existencia parcial de una filiación no constituye ningún inconveniente. En efecto, la dimensión dinástica de esta filiación aunque plausible en teoría ${ }^{50}$, no es indispensable. Es más, en la práctica institucional de la Unión Europea, y más concretamente del Consejo Europeo, esta filiación dinástica es desaconsejable. Así, es probable que dicha filiación dinástica, si hubiera existido, habría creado tensiones o escepticismo por parte de los Estados miembros que han adoptado el sistema republicano, y críticas de numerosos ciudadanos en cuanto al carácter poco democrático de este tipo de filiación.

Por los motivos arriba mencionados, se puede pensar que la inexistencia de filiación dinástica resulta de una voluntad clara en las instituciones europeas de no permitir la posibilidad de una filiación dinástica para el Presidente del Consejo europeo. En cuanto a la voluntad de promover las referencias a las filosofías e ideologías originarias de la Unión Europea y que los presidentes del Consejo europeo se reivindiquen como los sucesores de los padres fundadores, puede interpretarse como una compensación de la ausencia de filiación dinástica. Además, hay que reconocer que el recurso a esta filiación es muy hábil y muy eficaz, sobre todo respecto a los ciudadanos europeos que consideran a los padres fundadores como referencias fiables y representativas en Europa. Gracias a este fenómeno, los presidentes del Consejo Europeo pueden reforzar su crédito político y sus compromisos europeos y gozar de una real filiación.

Podemos afirmar que los Presidentes del Consejo Europeo gozan de una filiación parcial pero realmente pertinente. Esta realidad, que aparta las hipótesis radicales de existencia o de ausencia total de filiación, parece a nuestro juicio, como perfectamente adecuada a los presidentes del Consejo Europeo. En efecto, por una parte, una existencia global de filiación que abarcaría los dos matices estudiados en este apartado hubiera provocado confusiones y críticas contra su carácter antidemocrático. Por otra parte, la inexistencia total de filiación con la negación de la filiación ideológica y filosófica de los padres fundadores de la Unión Europea, habría restado credibilidad y fuerza a los distintos Presidentes del Consejo Europeo. Finalmente, el equilibrio y la compensación encontrados, nos parecen satisfactorios y merecen ser preservados para garantizar a los Presidentes del Consejo Europeo una fuente de autoridad política, nada superflua.

\section{La imperfección del sistema de designación}

El problema planteado por el modo de designación del presidente del Consejo europea influencia obviamente a la emergencia institucional de este cargo y se resume a la alternativa ofrecida hasta 20 io de un sistema de lista y el sistema de elección vigente desde la entrada en vigor del Tratado de Lisboa.

La designación del Presidente del Consejo Europeo, según el sistema de lista, se basa en un sistema de atribución automática y rotativa del mandato europeo ${ }^{5 \mathrm{I}}$. Este sistema

\footnotetext{
${ }^{50}$ En efecto, el Presidente del Consejo europeo, el Presidente de la Comisión o los Jefes de Estado o de Gobierno considerados individualmente como personas, podrían perfectamente justificar su presencia en el Consejo por el hecho de la herencia dinástica del cargo.

${ }^{51}$ La gran mayoría de los Jefes de Estado o de Gobierno miembros de la Unión europea han sido designados Presidente del Consejo europeo mediante el sistema de lista. España aseguró en tres ocasiones la presidencia del Consejo europeo, presidencia encarnada en I989 y I995 por el socialista Felipe González, y en 2002 por el conservador José María Aznar. Entre enero de 1975 y diciembre de 2009 , Francia fue seis veces Presidente del Consejo europeo en I979, I984, I989, I995, 2000 y 2008. En realidad el Consejo europeo tuvo, durante este periodo, 4 Presidentes franceses : el Presidente Giscard d'Estaing, entre I974 y I98I, el Presidente Mitterrand de I98I a I995, el Presidente Chirac de I995 a 2007, y por fin el Presidente Sarkozy desde 2007. Vid.
} 
está directamente inspirado de la presidencia por turno del Consejo de Ministros instaurado por el Tratado CECA y confirmado en el Tratado de Roma ${ }^{52}$. El sistema de elección debe permitir la designación del Presidente del Consejo Europeo mediante un proceso electoral organizado a nivel europeo, según las reglas electorales dictadas en los Tratados europeos ${ }^{53}$.

Por una parte, ante las dudas y los rodeos para determinar y establecer un sistema de designación para el Presidente del Consejo Europeo, los Jefes de Estado o de Gobierno han optado por aplicar un sistema de lista que, aunque vigente desde I974, calificamos de transitorio. En efecto, si la solución elegida ha permitido, en un principio, compensar de manera eficaz los problemas para elegir el Presidente del Consejo Europeo, se ha revelado a lo largo de los años y con las sucesivas ampliaciones, totalmente inadecuada. Por otra parte, la elección del Presidente del Consejo Europeo ha sido un sistema evocado y deseado desde la creación en 1974 del Consejo Europeo ${ }^{54}$. En efecto, considerando el papel importante y sobre todo emblemático del cargo, no se ha considerado adecuado una designación por nominación del Presidente del Consejo Europeo. Sin embargo, la imposibilidad de los Jefes de Estado o de Gobierno a ponerse de acuerdo sobre un mecanismo electoral concreto, ha dificultado la entrada en vigor y la aplicación de un sistema de elección para el Presidente del Consejo Europeo. El Tratado reformado de la Unión Europea propone en su artículo i5 este sistema novedoso ${ }^{55}$.

En este apartado queremos confrontar las especificidades y criterios que caracterizan un sistema original de designación procedente de una lista, con un sistema de elección, inexistente durante los treinta primeros años de existencia del Consejo Europeo. La primera característica es la diversidad de los protagonistas que intervienen en la designación del Presidente del Consejo Europeo. El segundo elemento característico de la designación del Presidente del Consejo Europeo es el alcance institucional europeo de su designación. Ahora bien, estas características tienen consecuencias distintas según que se aplique una designación por lista o por elección del presidente del Consejo Europeo.

D-G. LAVROFF, Le droit constitutionnel de la $V^{\circ}$ République, Paris : Dalloz, I995, y D. CHAGNOLLAUD, J-L. QUERMONNE, op. cit.

${ }^{2}$ Vid. P. MANIN, Les communautés européennes, l’Union européenne : Droit institutionnel, Paris : Pedone, I995, p. I68 a I69.

${ }^{53}$ En cambio, la opción de organizar una elección, para designar al Presidente del Consejo europeo, nunca ha sido instituida oficialmente por los Tratados europeos, lo que explica que, al día de hoy, ningún Presidente del Consejo europeo ha sido elegido.

${ }^{54}$ Las hipótesis y teorías para instaurar una elección del Presidente del Consejo europeo son númerosas y variadas, lo que explica que la elección pueda ser considerada como un sistema deseable pero inaplicado. Así, en I979, el «Informe de los tres Sabios» también examino la posibilidad de establecer el sistema de elección del Presidente del Consejo europeo, subrayando, sin embargo, las posibles dificultades que plantearía dicha elección. Vid. «Rapport des trois sages sur les institutions européennes», European NAvigator (ENA) [en línea],I980, disponible en: <http://www.ena.lu/rapport-institutions-europeennes-octobre-I979ого00290I.html>, (consultado en junio de 2008). Otro informe, de los directores de los institutos de estudios internacionales, apoyaba la idea de la elección del Presidente del Consejo europeo, realizada esta vez al sufragio universal indirecto, por los propios miembros del Consejo europeo. Vid. B. TAULEGNE, op. cit., p. 240. En I999, Jean-Louis Quermonne, reafirmaba la necesidad de elegir el Presidente del Consejo europeo, por los Jefes de Estado o Gobierno. Vid. «Rapport Quermonne sur l'Union européenne en quête d'institutions légitimes et efficaces», Paris : La Documentation française, Commissariat général du plan, octobre I999.

${ }^{55}$ La idea de elegir el Presidente del Consejo europeo es un concepto impulsado con fuerza durante el debate en la convención para el futuro de Europa. En efecto, algunos convencionales apoyaron la idea de la elección del Presidente al sufragio universal directo. Otros convencionales eran partidarios de elegir un único Presidente con la fusión del cargo de Presidente del Consejo europeo con el de Presidente de la Comisión europea. Vid. E. de PONCINS, Vers une Constitution européenne, Paris : Io/I8, 2003, p. I35. Véase R. BADINTER, «La présidence à deux tête», diario Le Monde [en línea], I2 de febrero de 2003, disponible en :<http://abonnes.lemonde.fr/cgibin/ACHATS/acheter.cgi?offre=ARCHIVES\&type_item=ART_ARCH_3OJ\& objet_id=792035>, (consultado en junio de 2008) y A. LEPARMENTIER, «L'idée d'un seul Président de l'Union revient à la Convention», diario Le Monde [en línea], 6 de mayo de 2003, disponible en : $<$ http://abonnes.lemonde.fr/web/recherche_resultats/I,I3-O,I-O,O.html>, (consultado en junio de 2008). 


\section{IV.I La pérdida de la ilusión democrática con la designación por lista del Presidente del Consejo Europeo}

Los protagonistas de la designación por lista del Presidente del Consejo Europeo se deducen del artículo 203 del TCE que dispone que «La presidencia se ejercerá por rotación por cada Estado miembro en el Consejo durante un período de seis meses según un orden que determinará el Consejo por unanimidad». Al principio, las rotaciones de las presidencias se hacían según el orden alfabético ${ }^{56}$ de los Estados miembros. Pero este sistema fue abandonado por el Acta única europea para privilegiar una alternancia entre el primer y el segundo semestre y evitar que un mismo país tenga que presidir el Consejo Europeo

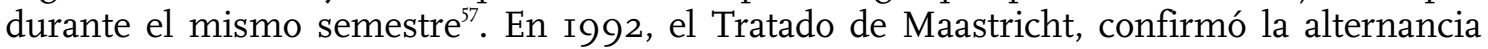
entre los dos semestres y dejó toda la libertad al Consejo para fijar los turnos de presidencia para cada país ${ }^{58}$, respetando un equilibrio entre las presidencias de los pequeños y de los grandes países.

El sistema de designación por lista del Presidente del Consejo Europeo permite destacar dos protagonistas principales.

En primer lugar, el Consejo de la Unión Europea detiene el protagonismo principal. Es él quien debe adoptar una decisión que fija el orden de rotación de las presidencias. Así, en enero de 2007 , el Consejo adoptó una decisión que fija el orden de ejercicio de las presidencias de 2007 a $2020^{59}$. El inconveniente de este protagonismo es que mantiene la dependencia institucional del Consejo Europeo hacia el Consejo de la Unión Europea, mediante un procedimiento totalmente desprovisto de fundamento democrático ${ }^{60}$. En cambio, se puede conceder como ventaja a la participación del Consejo de la Unión Europea a la designación del Presidente del Consejo Europeo la coherencia de esta designación, puesto que se ha establecido que el país cuyo Jefe de Estado o de Gobierno ejerce la presidencia del Consejo Europeo debe ser al mismo tiempo, el que preside el Consejo de Ministro.

En segundo lugar, los propios Jefes de Estado o de Gobierno miembros del Consejo Europeo son los otros protagonistas al auto-otorgarse la presidencia del Consejo Europeo en función de la decisión del Consejo de la Unión Europea. Este protagonismo en la designación del Presidente del Consejo Europeo es indispensable ya que es totalmente comprensible que el Consejo Europeo tenga que intervenir en la designación de su propio Presidente. La práctica ha limitado este protagonismo a un papel meramente protocolario

\footnotetext{
${ }^{56}$ Según los idiomas nacionales.

${ }^{57}$ El segundo semestre está considerado como más duro que el primer semestre. Vid. Y. DOUTRIAUX y C. LEQUESNE, op. cit., p. 26.

${ }^{58}$ Vid. «Decisión 95/2/CE del Consejo de I de enero de I995 por la que se fija el orden de ejercicio de la Presidencia del Consejo», Diario Oficial de las Comunidades Europeas, $\mathrm{n}^{\circ} \mathrm{L}$ I, I de enero de I995, p. 220. El turno tenía previsto Francia (I semestre I995) España (2 semestre I995) Italia (I semestre I996) Irlanda (2 semestre I996) Holanda (I semestre 1997) Luxemburgo (2 semestre I997) Reino Unido (I semestre I998) Austria(2 semestre I998) Alemania(I semestre I999) Finlandia (2 semestre I999) Portugal (I semestre 2000) Francia (2 semestre 2000) Suecia (I semestre 200I) Bélgica (2 semestre 200I) España (I semestre 2002) Dinamarca (2 semestre 2002) Grecia(I semestre 2003) Italia (2 semestre 2003) Irlanda (I semestre 2004) Holanda (2 semestre 2004) Luxemburgo (I semestre 2005) Reino Unido (2 semestre 2005) Austria (I semestre 2006) Finlandia (2 semestre 2006).

${ }^{59} \mathrm{Vid}$. «Decisión 2007/5/CE del Consejo de I de enero de 2007 por la que se fija el orden de ejercicio de la Presidencia del Consejo», Diario Oficial de las Comunidades Europeas, n L I, 4 de enero de 2007, p. II-I2.

${ }^{60}$ Ya que el Consejo impone la designación del Presidente del Consejo europeo en función de una rotación sucesiva entre todos los Estados miembros de la Unión europea. Esta disposición que fue vigente en la práctica durante mucho tiempo, está «convencionalizada» por el Tratado de Maastricht. Vid. V. CONSTANTINESCO, Traité de l’Union européenne, commentaire article par article, Paris : Economica, I995, p. 76.
} 
ya que los Jefes de Estado o de Gobierno no pueden, en teoría modificar o rechazar la designación, aunque en la práctica se hayan tolerado unos intercambios de presidencia por motivos electorales. En general el protagonismo de los Jefes de Estado o de Gobierno que van a ejercer la presidencia se limita a la participación a una pequeña ceremonia protocolaria durante la cual el precedente Presidente traspasa el «testigo» al siguiente Presidente. En realidad, la gran ventaja de este protagonismo es permitir a cada nuevo Presidente del Consejo Europeo tomar en cuenta que su nuevo cargo supone «un deber $y$ una contribución particular de cada Estado miembro al buen funcionamiento de las instituciones comunitarias» ${ }^{6 \mathrm{I}}$.

Los protagonismos del Consejo de la Unión Europea así como de los Jefes de Estado o de Gobierno miembros del Consejo Europeo ilustran un sistema que, en su tiempo, tuvo su lógica y su utilidad para fomentar una ilusión democrática de la designación del presidente del Consejo Europeo. Si el papel de dichos protagonistas y los procedimientos nos parecen hoy inadaptados y un poco anacrónicos, no criticamos la participación de dichas instituciones a la designación del Presidente del Consejo Europeo. En efecto, consideramos que el protagonismo del Consejo de la Unión Europea es totalmente justificado si se consideran los vínculos institucionales estrechos entre ambos Consejos y ambas presidencias. En cuanto al protagonismo del propio Consejo Europeo en la designación de su Presidente, lo consideramos como totalmente lógico. Finalmente, apreciamos la diversidad de los protagonistas que intervienen en la designación por lista del Presidente del Consejo Europeo. En esta línea y en con la entrada en vigor del Tratado de Lisboa, podría ser interesante la participación de otro protagonista como por ejemplo el Parlamento Europeo, de manera a preservar la diversidad de los protagonistas que intervienen en la designación del Presidente del Consejo Europeo.

\section{IV.2 La insuficiencia del carácter democrático de la elección del Presidente del Consejo Europeo}

A pesar de la oposición de los pequeños países, el apoyo determinante del Presidente español, José María Aznar, del Primer ministro británico Tony Blair ${ }^{62}$, y del Presidente francés Jacques Chirac a favor de la elección del Presidente del Consejo Europeo permitió al final imponer esta idea ${ }^{63}$ durante la conferencia Intergubernamental de octubre $2004^{64}$. El acuerdo de los Jefes de Estado o de Gobierno sobre una elección al sufragio universal indirecto realizada por los propios miembros del Consejo Europeo permitió la adopción del artículo I-2I de la Constitución europea que disponía claramente que «el Consejo Europeo elegirá a su Presidente por mayoría cualificada (...)» ${ }^{65}$. El Tratado reformado de

\footnotetext{
${ }^{61}$ Vid. ANÓNIMO, «La rotation de la presidence», Presidencia luxemburguesa de la U.E. de 2005 [en línea], disponible en : <http://www.eu2005.lu/fr/presidence/la_presidence/rotation_presidence/index.html>, (consultado en julio de 2008).

${ }^{62}$ Vid. H. de BRESSON, «Britaniques et espagnols approuvent une double présidence de l'Europe», diario Le Monde [en línea], I7 de enero de 2003, disponible en: <http://abonnes.lemonde.fr/cgibin/ACHATS/acheter.cgi?offre=ARCHIVES\&type_item=ART_ARCH_30J\&objet_id=788539>, (consultado en junio de 2008).

${ }_{3}^{6}$ Vid. O. DUHAMEL, Pour l'Europe : le texte intégral de la Constitution expliqué et commenté, Paris : Seuil, 2003, p. I80 y I8I.

${ }^{64}$ Vid. T. FERENCZI, L. ZECCHINI, «Président du Conseil, ministre des affaires étrangeres les nouvelles têtes de l'Europe», diario Le Monde [en línea], I3 diciembre de 2003, disponible en : $<$ http://abonnes.lemonde.fr/cgi-

bin/ACHATS/acheter.cgi?offre=ARCHIVES\&type_item=ART_ARCH_30J\&objet_id=83I579>, (consultado en junio de 2008), y T. FERENCZI, «Des sujets de controverse persistants», diario Le Monde [en línea], 7 de octubre de 2003, disponible en : <http://abonnes.lemonde.fr/web/recherche_resultats/I,I3-O,I-O,o.html>, (consultado en junio de 2008).

${ }^{65}$ Según las reglas establecidas en el Tratado constitucional, el Presidente del Consejo europeo quedaría elegido a la condición de obtener el voto de los $2 / 3$ de los Estados, representando al menos los $3 / 5$ de la
} 
la Unión Europea recoge esta disposición en su artículo i5 y confirma la elección del Presidente del Consejo Europeo por el propio Consejo Europeo.

En el sistema de elección, el Tratado de Lisboa contempla la participación de un sólo protagonista. Si el Consejo de la Unión Europea ya no participa a la designación del Presidente del Consejo Europeo, el Consejo Europeo conserva su participación y amplía sus prerrogativas ya que es él quien decide quién será su Presidente. El procedimiento, más democrático, esconde en realidad un protagonismo monopolizado en las manos del sólo Consejo Europeo, sin control ni información de otras instituciones. La limitación del número de protagonistas en la elección del Presidente del Consejo Europeo tiene el inconveniente de romper la regla de la diversidad de protagonistas para la designación de los demás miembros del Consejo Europeo. Además, esta elección limitada a la sola participación del Consejo Europeo no tiende a desarrollar las relaciones interinstitucionales, y encierra el Consejo Europeo en una vida institucional desconectada de las demás instituciones.

El abandono del sistema de lista a favor del sistema de elección aporta un carácter democrático a la designación del Presidente del Consejo Europeo. Sin embargo, el hecho de que sólo haya un único protagonista en la elección del Presidente del Consejo Europeo nos parece bastante insuficiente. Por eso lamentamos la opción elegida por el Tratado de Lisboa de abandonar la diversidad de los protagonistas en la elección del Presidente del Consejo Europeo. Pensamos que obscurece el carácter democrático otorgado por la elección a la designación del presidente del Consejo Europeo y que sería útil que participaran otras instituciones en dicho procedimiento, de forma más o menos formal. En este sentido, es interesante recordar que durante la convención para el futuro de Europa ${ }^{66}$, el Presidente Giscard d'Estaing había emitido la idea original de realizar la elección del Presidente del Consejo Europeo al sufragio universal indirecto, por un Congreso de los pueblos, compuesto por parlamentarios europeos y nacionales ${ }^{67}$, lo que suponía más protagonistas. Compartimos y apoyamos esta idea.

Antes de recurrir a una reforma institucional, creemos que la práctica podría permitir la intervención de ciertas instituciones europeas para seguir el proceso de elección y otorgar a esta designación un toque protocolario que el Tratado de Lisboa no le da. Así, como depositaria institucional de los Tratados europeos, pensamos que la Comisión Europea podría tener un papel interesante en la elección del Presidente del Consejo Europeo. Se podría imaginar un sistema en el que la Comisión reunida, tomaría juramento del nuevo Presidente del Consejo Europeo. También consideramos como posible la integración de un sistema de información del Parlamento Europeo y/o del Consejo de la Unión Europea sobre el procedimiento de la elección del Presidente del Consejo Europeo. Queremos indicar por fin que, aunque todavía no haya la madurez institucional suficiente, la elección del Presidente del Consejo Europeo debería contar con el protagonismo más ambicioso de los pueblos europeos. De hecho, desde I974, y en varias ocasiones, el Presidente Giscard d'Estaing, padre del Consejo Europeo, ha abogado en favor de la elección del Presidente del Consejo Europeo, al sufragio universal directo, es decir, un

población. Este sistema asegura así al Presidente del Consejo europeo elegido según este sistema beneficiar de un amplio apoyo en el seno del Consejo europeo y de los Jefes de Estado y de Gobierno. Vid. E. de PONCINS, op. cit., p. I34.

${ }^{66}$ Vid. V. GISCARD d'ESTAING, «La convention européenne à mi parcours», diario Le Monde [en línea], I4 de enero de 2003, disponible en : <http://abonnes.lemonde.fr/web/recherche_resultats/I,I3-O,I-O,O.html>, (consultado en junio de 2008).

${ }^{67}$ Proyecto rechazado por los convencionales. Vid. V. GISCARD d'ESTAING, La Constitution pour l'Europe, Paris : Albin Michel, 2003. 
Presidente elegido directamente por los ciudadanos europeos ${ }^{68}$. Estamos convencidos de que este protagonismo de los pueblos europeos en el procedimiento de elección del Presidente del Consejo Europeo beneficiaría mucho a la figura del Presidente del Consejo Europeo debido a la potencia democrática que supondría dicho protagonismo.

\section{IV.3 El no-reconocimiento convencional de la designación por lista del Presidente del Consejo Europeo como miembro del Consejo Europeo}

Según el artículo 4 del TUE, «El Consejo Europeo estará compuesto por los Jefes de Estado o de Gobierno de los Estados miembros, así como por el Presidente de la Comisión. Éstos estarán asistidos por los Ministros de Asuntos Exteriores de los Estados miembros y por un miembro de la Comisión. El Consejo Europeo se reunirá (...), bajo la presidencia del Jefe de Estado o de Gobierno del Estado miembro que ejerza la presidencia del Consejo». Concretamente, y como lo dispone el artículo 203 del TCE «La presidencia se ejercerá por rotación por cada Estado miembro en el Consejo durante un período de seis meses según un orden que determinará el Consejo por unanimidad». Estas disposiciones convencionales permiten diseñar el alcance de la lista que sirve de base para el mandato del Presidente del Consejo Europeo.

Por una parte, el sistema de lista supone una designación exclusiva es decir que cuando se designa al Presidente del Consejo Europeo no se realiza ninguna otra designación simultánea. Dicho de otro modo, si para ser Presidente del Consejo Europeo el Tratado impone que el candidato sea Jefe de Estado o de Gobierno, la designación del Presidente del Consejo Europeo no se hace al mismo momento que la elección del Jefe de Estado o de Gobierno. También se puede notar que el sistema de designación del Presidente del Consejo Europeo adoptado en los Tratados excluye el recurso a criterios susceptibles de ayudar en la selección de los candidatos. En estas circunstancias, cabe admitir que el alcance europeo de la designación por lista es bastante matizado. En efecto, es cierto que la designación del Presidente del Consejo Europeo supone un cierto alcance europeo debido a las funciones europeas que va a desempeñar. Sin embargo, dicha selección no se apoya sobre criterios que puedan subrayar la responsabilidad y el compromiso europeo del futuro Presidente, dándole a su designación un fuerte alcance europeo; al contrario, el sistema de lista de atribución por turno de la presidencia del Consejo Europeo se basa sobre criterios que hacen resaltar la dimensión nacional de la designación ${ }^{69}$. Además, el modo de designación exclusivo, según el sistema de lista, resta bastante alcance europeo al nuevo Presidente, otorgando al contrario, a la designación del Jefe de Estado o de Gobierno, un alcance nacional más fuerte sobre el escenario europeo.

Por otra parte, es interesante notar que la designación por lista no goza de un alcance institucional suficiente. En efecto, el sistema de designación exclusivo permite centrar el reconocimiento convencional sólo al nivel de la designación del Presidente del Consejo Europeo, no obstante, el artículo 4 del TUE no reconoce la condición institucional de miembro del Consejo Europeo del Presidente del Consejo Europeo, al menos de manera explícita. Aunque la práctica haya confirmado desde hace muchos años, el alcance institucional de la designación del Presidente del Consejo Europeo como miembro del Consejo Europeo, el no-reconocimiento de su condición institucional disminuye la

\footnotetext{
${ }^{68}$ Para el Presidente Giscard d'Estaing «La elección del Presidente del Consejo europeo al sufragio universal directo debe completar la de la Asamblea europea». Vid. V. GISCARD d' ESTAING, Presidente de la República francesa, entrevistado por ANÓNIMO, [s.1.] : La Libre Belgique, 23 de mayo de i984. Véase también PONCINS. E., op. cit, p.I35.

${ }_{9}^{6}$ Primero solo pueden verse atribuido a la presidencia del Consejo europeo sus propios miembros. Esto excluye de manera radical la hipótesis de tener un Presidente que no sea miembro del Consejo europeo. El segundo criterio limita la atribución de la presidencia a los solos Jefes de Estado y de Gobierno miembros del Consejo europeo, es decir, a los Jefes de Estado y de Gobierno cuyo país es miembro de la Unión europea. Esto significa que no pueden ejercer la presidencia del Consejo europeo ni los Ministros nacionales, ni el Presidente de la Comisión, ni el Comisario europeo, y eso a pesar de ser miembros de pleno derecho del Consejo europeo.
} 
dimensión institucional del cargo de Presidente del Consejo Europeo y afecta a su designación.

La ausencia de alcance institucional europeo de la designación por lista del Presidente del Consejo Europeo no nos satisface. Por lo que se refiere al alcance institucional europeo de la designación del Presidente del Consejo Europeo, consideramos que hubiera sido bastante difícil mejorarlo mientras se mantenga el sistema de designación por lista. Al haberse mantenido este sistema, creemos probable que el cargo de Presidente del Consejo Europeo hubiera seguido careciendo del alcance institucional europeo que debería corresponderle.

\section{IV.4 El reconocimiento convencional de la elección del Presidente del Consejo Europeo como miembro del Consejo Europeo}

Según el artículo I5 del Tratado reformado de la Unión Europea:

«2. El Consejo Europeo estará compuesto por los Jefes de Estado o de Gobierno de los Estados miembros, así como por su Presidente y por el Presidente de la Comisión. Participará en sus trabajos el Alto Representante de la Unión para Asuntos Exteriores y Política de Seguridad.

5. El Consejo Europeo elegirá a su Presidente por mayoría cualificada para un mandato de dos años y medio, que podrá renovarse una sola vez. En caso de impedimento o falta grave, el Consejo Europeo podrá poner fin a su mandato por el mismo procedimiento.»

El alcance de la elección del Presidente del Consejo Europeo se encuentra radicalmente modificado por este modo de designación y merece pues unos comentarios.

Primero, el alcance europeo se encuentra notablemente reforzado. Por una parte, el sistema de elección mantiene una designación exclusiva es decir que cuando se designe al Presidente del Consejo Europeo no se realiza ninguna otra designación simultánea. Sin embargo, el Tratado reformado de la Unión Europea impone que el Presidente elegido no tenga ningún mandato nacional. Esto significa que el modo de elección exclusivo, realizado exclusivamente al nivel europeo, devuelve un alcance europeo al nuevo Presidente. Es importante subrayar también que los convencionales no han querido imponer un criterio restrictivo en el texto del Tratado, como por ejemplo, la obligación del candidato a la presidencia de haber sido miembro del Consejo Europeo durante dos años ${ }^{70}$. En cambio, parece evidente que el candidato tendrá que conocer el funcionamiento de la institución. Además, la designación del Presidente del Consejo Europeo tal y como está prevista en el Tratado reformado de la Unión Europea estará sometida a la declaración n 6 que tiene previsto que «En la elección de las personas que habrán de desempeñar los cargos de Presidente del Consejo Europeo, (...) deberá tenerse debidamente en cuenta la necesidad de respetar la diversidad geográfica y demográfica de la Unión y de sus Estados miembros» ${ }^{7 \mathrm{~T}}$. La aplicación de dichos criterios permitirá con la práctica insistir en la representatividad y el compromiso europeo del futuro Presidente, otorgando a su elección un importante alcance europeo ${ }^{72}$.

\footnotetext{
${ }^{70}$ Lo que en teoría deja abierto la posibilidad de elegir un Presidente que nunca ha sido miembro del Consejo europeo. Sin embargo, en la práctica, podemos pensar que los primeros candidatos a la presidencia serán miembros o ex-miembros del Consejo europeo. Vid. E. de PONCINS, op. cit., p. I35 y I36.

${ }^{71}$ Véase «Declaración 6 relativa a los apartados 5 y 6 del artículo I5, a los apartados 6 y 7 del artículo I7 y al artículo I8 del Tratado de la Unión Europea», Eur-Lex [en línea], disponible en : < http://eurlex.europa.eu/LexUriServ/LexUriServ.do?uri=OJ:C:2008:II5:०00I:0I:ES:HTML>, (consultado en julio de 2008).

${ }^{72}$ De momento se barajan dos personalidades susceptibles de convertirse en primer Presidente del Consejo europeo elegido. Se trata del actual Primer ministro luxemburgués, Jean-Claude Juncker, y del ex Primer ministro inglés Tony Blair. También se evoca con insistencia el nombre del ex - Presidente del Gobierno
} 
Luego, el alcance institucional está explícitamente ampliado gracias a las disposiciones del Tratado reformado de la Unión Europea. En efecto, la elección exclusiva limita el reconocimiento institucional de la condición de Presidente del Consejo Europeo al Tratado reformado de la Unión Europea. Ahora bien, este reconocimiento convencional de la condición institucional está realizado por el artículo i5 que instaura formalmente la condición institucional de miembro del Consejo Europeo del Presidente del Consejo Europeo. De este modo, se establece con firmeza el alcance institucional de la elección del Presidente del Consejo Europeo.

Sobre la base de los análisis anteriores, consideramos que el alcance institucional europeo de la elección del Presidente del Consejo Europeo se encuentra considerablemente mejorado gracias al reconocimiento en las disposiciones del TRUE, de la elección del Presidente del Consejo Europeo como miembro del Consejo Europeo. Así, la elección del Presidente del Consejo Europeo encuentra en el Tratado reformado de la Unión Europea, el alcance institucional europeo que le faltaba en el sistema de lista.

\section{Conclusiones}

I- Nuestra reflexión sobre la evolución política y jurídica del Presidente del Consejo europeo desemboca sobre dos premisas clave:

Primero, el Presidente del Consejo Europeo se ha impuesto como el «mascaron de proa institucional» del Consejo europeo.

Segundo el Presidente del Consejo europeo aparece como una figura política y jurídica emergente en el escenario institucional europeo que necesita consolidarse.

2- Tanto en el modelo de la «personificación estatal» como en el modelo de «personificación personal», el Presidente del Consejo Europeo es indiscutiblemente el mascaron de proa de esta institución. La revolución jurídica introducida por el Tratado de Lisboa no ha alterado esta percepción y hasta podríamos decir que la ha reforzado en beneficio del Consejo europeo.

3- La mutación del modelo jurídico de Presidente del Consejo europeo confirma la dinámica de emergencia institucional de este cargo. Sin embargo, si reconocemos que el modelo de la «personificación estatal» de presidencia del Consejo Europeo era anticuado, y desgastado por los efectos negativos producidos sobre el buen funcionamiento del Consejo Europeo, tenemos que ser prudente en cuanto a la aplicación del modelo de «personificación personal» de la Presidencia del Consejo Europeo. Esta consolidación del cargo de presidente del consejo europeo no puede hacerse en detrimento de la propia institución del Consejo europeo, es decir que el protagonismo del consejo europeo no puede encontrarse monopolizado y derivado hacia la persona de su presidente. La consolidación de la figura de presidente del Consejo europeo tendrá que efectuarse siempre en el justo equilibrio entre lo comunitario y lo intergubernamental.

español Felipe González. El Presidente Nicolás Sarkozy que asumirá la presidencia del Consejo europeo en el momento de la elección del Presidente del Consejo europeo ha concedido que Tony Blair era «el más europeo de los ingleses (...) que podamos pensar en él [para asumir el cargo] es bastante inteligente». Por lo que se refiere a Jean Claude Juncker, el Presidente Sarkozy subrayo que el hecho de que el Primer ministro luxemburgués sea miembro del Consejo europeo «da una cultura, una historia y pues que pueda ser el primer Presidente del Consejo es una idea inteligente». Vid. T. FERENCZI, «Président du Conseil européen et haut représentant, des fonctions convoitées par les Vingt-Sept», diario Le Monde [en línea], 2I de octubre de 2007, disponible en: <http://www.lemonde.fr/cgibin/ACHATS/acheter.cgi?offre=ARCHIVES\&type_item=ART_ARCH_3OJ\&objet_i $\mathrm{d}=\mathrm{I00965}$ I\&clef=ARC-TRK-NC_OI>, (consultado en junio de 2008). 
4- Como mascaron de proa del Consejo europeo, el presidente goza de una autoridad política mediocre que se explica principalmente por su clara falta de carisma. Esta debilidad política se encuentra parcialmente compensada con la búsqueda de una filiación política por parte de los Presidente del Consejo europeo, en las herencias de los Padres fundadores.

5- Excepto en un par de ocasiones, cabe reconocer que, el Presidente del Consejo Europeo no suscita suficiente«fascinación» 73 y credibilidad74, como para imponerse como una figura institucional carismática de la Unión Europea. La elección del belga Herman Van Rompuy no parece, de momento, derogar a esta regla. Una de las claves de la consolidación de la figura política y jurídica del presidente del consejo europeo está en una reconquista del aura carismática perdida desde los años 90. Eso supone en el caso del Presidente del Consejo Europeo, y considerando su posicionamiento institucional a mitad de camino entre lo comunitario y lo intergubernamental, una voluntad personal y política por desempeñar acciones impresionantes e históricas que conduzcan a ganar el «cariño» de los euro-ciudadanos y el reconocimiento de las demás instituciones europea. Por otra parte, y para consolidarse plenamente en el escenario institucional europeo, los presidentes del Consejo europeo deberán asumir plenamente la herencia política de los Padres fundadores.

6- En referencia al sistema de designación del presidente del Consejo europeo, la reforma institucional, impulsada en Lisboa, ha conducido al abandono de la diversidad de los protagonistas en este procedimiento. Esta característica criticable, tiene como consecuencia la perdida de la ilusión democrática de la designación por lista del Presidente del Consejo Europeo, sin no obstante, otorgar un carácter democrático suficiente a la elección del Presidente del Consejo Europeo. Sin embargo, el sistema de designación peculiar al que está sometido el presidente del Consejo europeo, tanto en el periodo anterior al Tratado de Lisboa como en el periodo actual, confirma la imagen de mascaron de proa de este cargo.

7- Los sistemas de designación del presidente del Consejo europeo han sido imaginados sin preocupaciones de buen funcionamiento institucional y desemboca en sistemas imperfectos que impiden a la figura del presidente del Consejo europeo imponerse en el escenario institucional europeo. Eso se ha podido comprobar en el sistema de designación por lista hasta 20ıo. Pero el sistema de elección previsto en el Tratado de Lisboa ha demostrado sus límites en el momento de la designación del Presidente Van Rompuy. En efecto, bajo las presiones del representante francés, el Consejo Europeo en vez de elegir a su Presidente por mayoría cualificada lo designo por consenso. Este desvío en la práctica institucional si debía confirmarse, impediría totalmente una consolidación útil y necesaria del cargo de Presidente del consejo europeo. La mejora institucional que supondría una verdadera elección del Presidente del Consejo europeo, al sufragio universal directo o indirecto, permitiría en nuestra opinión, una consolidación institucional definitiva de esta figura emblemática de la Unión europea.

8- Desde I974, la figura del Presidente del Consejo europeo se ha impuesto progresivamente en el escenario europeo obrando al frente de una institución que ha sido reconocida como tal solamente en 20I0. Los rasgos de su evolución jurídica y política son innegables. De hecho, la rivalidad pasada y presente existente entre el presidente del consejo europeo y el presidente de la Comisión europea, aunque injustificada y malsana para el buen funcionamiento institucional, confirma la trayectoria institucional exponencial efectuada desde 1974. Pertenece ahora a los futuros presidentes del Consejo europeo apoderarse de la función y diseñar el cargo a la altura de los grandes retos que debe afrontar la Unión europea.

\footnotetext{
${ }^{73}$ Debida a las cualidades personales y a la inteligencia de sus miembros.

${ }^{74}$ Debida a la fuerza de las ideas expresadas por el colegio.
} 